\title{
Mechanisms for Cross-Scaling, Flexibility and Social Learning in Building Resilience to Sea Level Rise: Case Study of Hampton Roads, Virginia
}

\author{
Carol Considine', Michelle Covi², Juita-Elena (Wie) Yusuf ${ }^{3}$ \\ ${ }^{1}$ Batten College of Engineering \& Technology, Old Dominion University, Norfolk, VA, USA \\ ${ }^{2}$ College of Sciences, Old Dominion University and Virginia Sea Grant Climate Adaptation and Resilience Program, Norfolk, \\ VA, USA \\ ${ }^{3}$ Strome College of Business, Old Dominion University, Norfolk, VA, USA \\ Email:cconsidi@odu.edu,mcovi@odu.edu,jyusuf@odu.edu
}

How to cite this paper: Considine, C. Covi, M. and Yusuf, J.-E. (2017) Mechanisms for Cross-Scaling, Flexibility and Social Learning in Building Resilience to Sea Level Rise: Case Study of Hampton Roads, Virginia. American Journal of Climate Change, 6 , 385-402.

https://doi.org/10.4236/ajcc.2017.62020

Received: December 13, 2016

Accepted: June 25, 2017

Published: June 28, 2017

Copyright (c) 2017 by authors and Scientific Research Publishing Inc. This work is licensed under the Creative Commons Attribution International License (CC BY 4.0).

http://creativecommons.org/licenses/by/4.0/

\begin{abstract}
This case study examines how the Hampton Roads Sea Level Rise Preparedness and Resilience Intergovernmental Planning Pilot Project, a whole-ofgovernment and whole-of-community approach to planning for and adapting to sea level rise, addressed coastal resilience in a southeastern Virginia watershed that spans multiple jurisdictions. Meeting the challenge of sea level rise requires that actors across multiple sectors-citizens, community organizations, industry and government-understand the risks and work together to make critical decisions regarding adaptation strategies and actions. The case study area includes Little Creek Amphibious Base, which is bordered by the cities of Norfolk and Virginia Beach. Adaptation responses to sea level rise by the military base and the local governments will impact each other and the residents of the area, but no cooperative agreements are in place for a joint or collaborative response. This case study examines public and private infrastructure at risk, the infrastructure interdependencies, and mechanisms for providing collaborative solutions. Engagement of area residents and other stakeholders is also integral to the process of adaptation, which includes educating about sea level rise risk and provides a mechanism for social learning that enables stakeholders to participate in critical adaptation decisions. The case study demonstrates a method to improve resiliency in the case study area and inform a regional, multi-sectoral response to sea level rise adaptation strategies.
\end{abstract}

\section{Keywords}

Sea Level Rise, Multi-Sectoral Adaptation, Hampton Roads, Critical 
Infrastructure, Social Learning, Socio-Ecological Resilience, Cross-Scaling

\section{Introduction: The Hampton Roads Region and Its Vulnerability to Sea Level Rise}

The Hampton Roads region is located in southeastern Virginia at the confluence of the Chesapeake Bay and Atlantic Ocean. As shown in Figure 1, it is home to 26 federal installations (DoD and non-DoD) and 17 municipal governments. It is recognized as being second only to New Orleans as the largest population center at the greatest risk to sea level rise [1]. Municipalities located adjacent to the Atlantic Ocean and Chesapeake Bay are already experiencing the impacts of sea level rise and many are proactively planning to mitigate sea level rise impacts. The Hampton Roads region is experiencing sea level rise at approximately twice the global rate [2] [3] [4]. This increased rate of sea level rise regionally is due to land subsidence and the slowing of the Gulf Stream [5] [6].

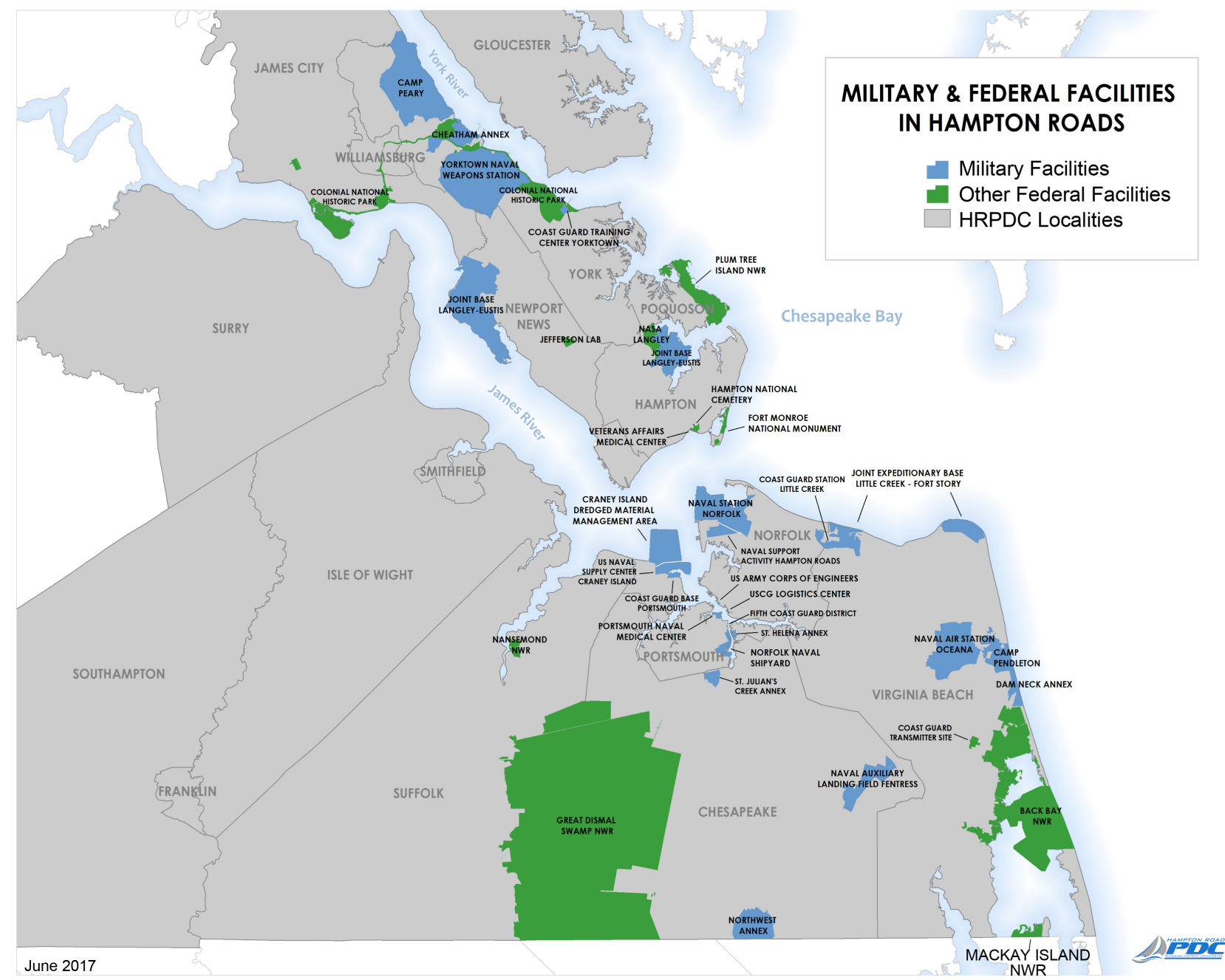

Figure 1. Hampton Roads municipalities and federal installations. Map produced by the staff of the Hampton Roads Planning District Commission, 2016. 
The seventeen jurisdictions in the Hampton Roads region have historically planned and governed independently of one another. Adaptation planning for sea level rise is no exception. Currently there is no entity coordinating sea level rise planning for the region. Instead, each municipality is determining their own sea level rise planning scenarios and evaluating adaptation strategies independently of one another. In addition, the Department of Defense has evaluated sea level rise impacts to Naval Station Norfolk, but the analysis does not include impacts to local adjacent municipalities.

While it is not unusual for local, state, and federal entities to limit their planning to jurisdictional boundaries, water is not bound by those same geographic constraints. Planning for sea level rise will require that local, state, and federal entities consider functional boundaries of ecosystems or watersheds, rather than political boundaries. This will require coordination between local, state, and federal entities so that actions of local municipalities do not interfere with one another or the mission readiness of federal entities in the local area. Sea level rise preparedness actions led by local municipalities, if coordinated with each other and the federal installations, can increase resiliency for the entire region. Coordination and collaboration between entities can help achieve optimal outcomes.

\section{Socio-Ecological Systems in Sea Level Rise Adaptation}

Approaching the problem from the perspective of socio-ecological resilience is an important element to such a coordinated and collaborative effort. Understanding resilience as both social and ecological is critical, as the resilience of a social system is related to the resilience of the ecological systems on which it depends [7] [8] [9]. Socio-ecological resilience refers to "the capacity of linked social-ecological systems to absorb recurrent disturbances such as hurricanes or floods so as to retain essential structures, processes, and feedbacks" [10] (p. 1036). More importantly, it represents the extent to which social-ecological systems have the capacity for learning and adaptation. Watersheds, and the human communities and institutions that reside in these watersheds, embody the linked social-ecological systems that are stressed by climate change and its associated impacts.

Socio-ecological resilience requires understanding at broader scales [10]. Furthermore, enhancing resilience requires multilevel (and we argue, multi-sectoral) networks to develop the social capital and support for the required political, legal, and economic frameworks [11] [12]. As such, the socio-ecological resilience perspective supports the decision framework we emphasize in this case study of coordinated collaborative planning that spans multiple watersheds, federal facilities and land, and cities. Adger et al. point to such coordination and collaboration as requiring sharing of the management and decision making authority, which in turn relies on cross-organizational interactions and cooperation [10].

Socio-ecological systems are linked systems of humans and nature. In coastal communities it is not unusual for human governance structures to overlap with 
ecological systems, thus creating a mismatch of scales. However, we need to consider mismatches of scale as a possible contributor to challenges in addressing issues related to human-nature interactions and socio-ecological resilience [13] [14] [15]. Cumming et al. define scale mismatch as taking place "when the scale of environmental variation and the scale of the social organization responsible for management are aligned in such a way that one or more functions of the social-ecological system are disrupted, inefficiencies occur, and/or important components of the system are lost" [14]. Mismatches of scale, particularly spatial mismatch, can apply in the context of sea level rise in coastal communities. The spatial mismatch relates to the scale of governance or governance boundaries and natural actions or watershed boundaries [13]. Spatial mismatch can also occur when there is a lack of communications between residents and stakeholders in neighboring communities [15].

The consequences of such mismatches, as is evident in our case study and other issues related to socio-ecological resilience, include:

"Mismatched organizations are frequently confronted with ecological situations in which they do not understand the nature of the problem, are incapable of managing effectively, or lack the necessary power to achieve the scale of management that is required. Territorial institutions in these circumstances are often reluctant to give up power, and fine-scale decisions seldom add up to the kind of cohesive action that is required for broadscale ecological management. Institutional confusion over the nature of the problem translates into a lack of clear responsibility for finding solutions" [14].

Beyond recognizing the root cause of a mismatch between ecological and institutional scales, resolving the scale mismatch may require institutional reorganization or governance structures that allows institutional cross-scaling and flexibility [14] [15]. Our case study describes an institutional arrangement, in the form of the Hampton Roads Sea Level Rise Preparedness and Resilience Intergovernmental Planning Pilot Project (also known as the Pilot Project), which created enabling conditions for cross-scaling and flexibility needed for co-management at the appropriate scale. Social learning is a critical aspect of socio-ecological resilience [9] and a key component of resolving scale mismatches [13] [14]. This social learning is an integral element of the Pilot Project institutional arrangement.

\section{The Hampton Roads Sea Level Rise Preparedness and Resilience Intergovernmental Planning Pilot Project}

The Pilot Project is a two year "whole-of-government" and "whole-of-community" effort to recommend a governance structure for holistic sea level rise planning in the Hampton Roads region. The Pilot Project was convened at Old Dominion University and is led by a Steering Committee comprised of high-level leaders at multiple levels of government (local, state, and federal) and from multiple sectors, including business, non-governmental, and civil society. The structure of the Pilot Project includes five working groups: Legal, Infrastructure, Land Use Planning, Citizen Engagement, and Public Health Working Groups. The Pilot Project is also supported by five advisory committees: Economic Im- 
pacts, Private Infrastructure, Municipal Planning, Science and Senior Advisory Committees.

The whole-of-government and whole-of-community framework of the Pilot Project was tested on the ground using a case study area that provided an appropriate context for local, state, and federal governments to work together. The Private Infrastructure Advisory Committee and the Infrastructure Citizen Engagement and Public Health Working Groups also used this case study area as their test bed.

\section{Case Study Overview}

The Little Creek/Pretty Lake area of Norfolk and Virginia Beach was chosen as the case study area primarily because its ecological boundaries extend across three management boundaries: two municipalities (City of Norfolk and City of Virginia Beach) and a federal installation, Naval Amphibious Base Little Creek, which is part of the Joint Expeditionary Base Little Creek-Fort Story. The watershed is a relatively large watershed area with a narrow inlet from the Chesapeake Bay that is located adjacent to the Little Creek Amphibious Base (see Figure 2). The case study area is relatively low lying, with an average elevation of

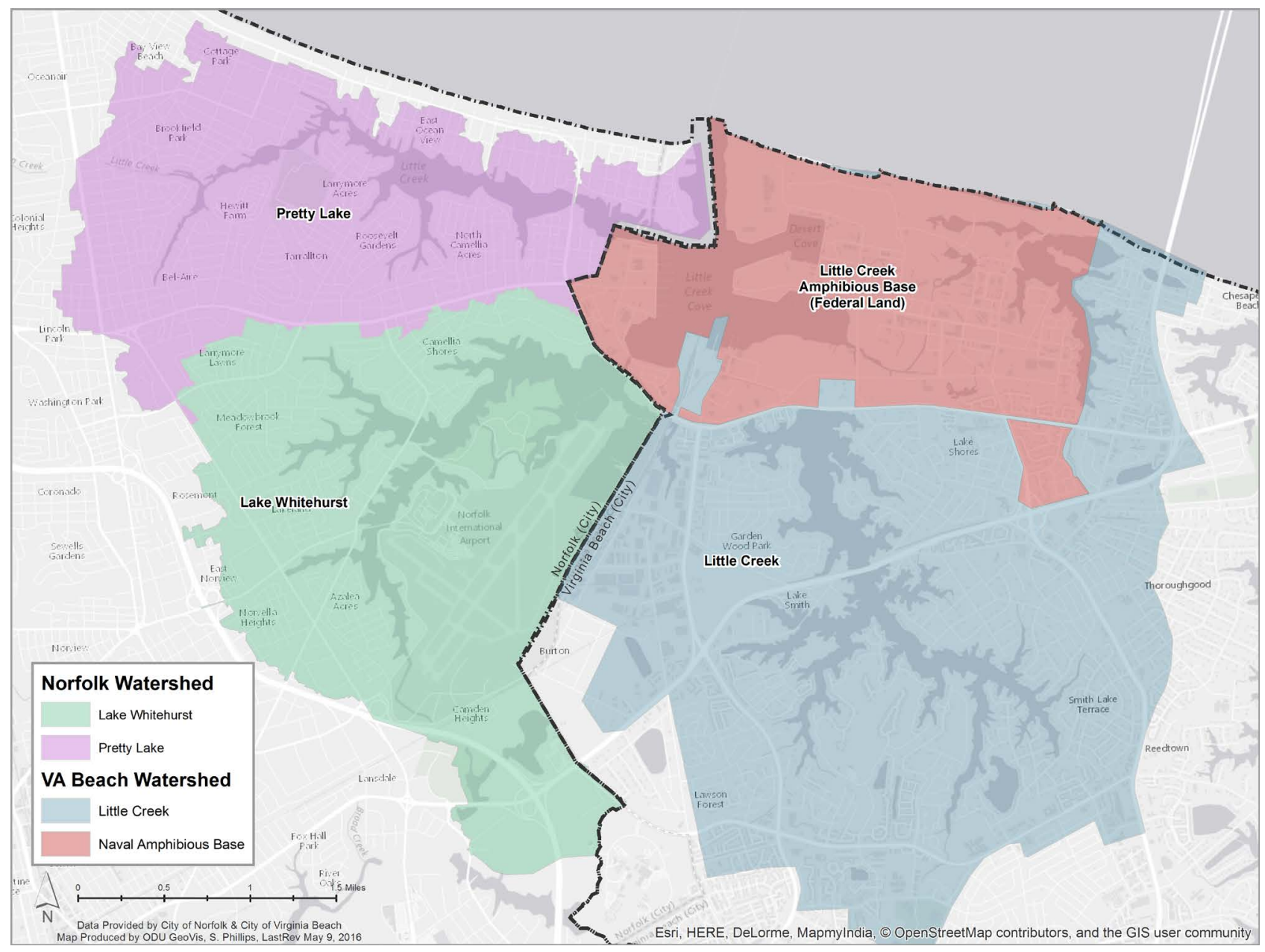

Figure 2. Little Creek/Pretty Lake case study area map. Produced by staff of the Old Dominion University Center for Geospatial and Visualization Computing. 
approximately 12 feet and is susceptible to flooding in major storm events.

\subsection{Social and Ecological Context}

The City of Norfolk has eight watersheds, two of which drain into the Little Creek/Pretty Lake ecological system. The Lake Whitehurst watershed drains approximately 4.5 square miles of area and contains one of Norfolk's eleven fresh water reservoirs that provide drinking water for Norfolk and adjacent communities. Pretty Lake watershed drains approximately four square miles of area and contains Pretty Lake, a tidally influenced brackish water lake, which is navigable by small watercraft [16]. The City of Virginia Beach has eight secondary watersheds; the Little Creek watershed drains approximately 8.1 square miles of area into the Pretty Lake/Little Creek ecological system and contains Lake Lawson and Lake Smith Recreational areas. The Little Creek Amphibious Base is approximately 3.3 square miles located near the center of the Pretty Lake/Little Creek ecological system and adjacent to the inlet of the system to the Chesapeake Bay. It is a major operating base for the Amphibious Forces in the United States Navy's Atlantic Fleet.

The Infrastructure Working Group selected four sea level rise and flooding scenarios as the basis for risk analysis and assessment: 1) sea level rise of 1.5 feet, 2) sea level rise of 1.5 feet with 100 year storm surge, 3) sea level rise of 3.0 feet, and 4) sea level rise of 3.0 feet with 100 year storm surge (see Figures 3-6).

\section{5' of Sea Level Rise Above Current Mean Higher High Water (MHHW)}

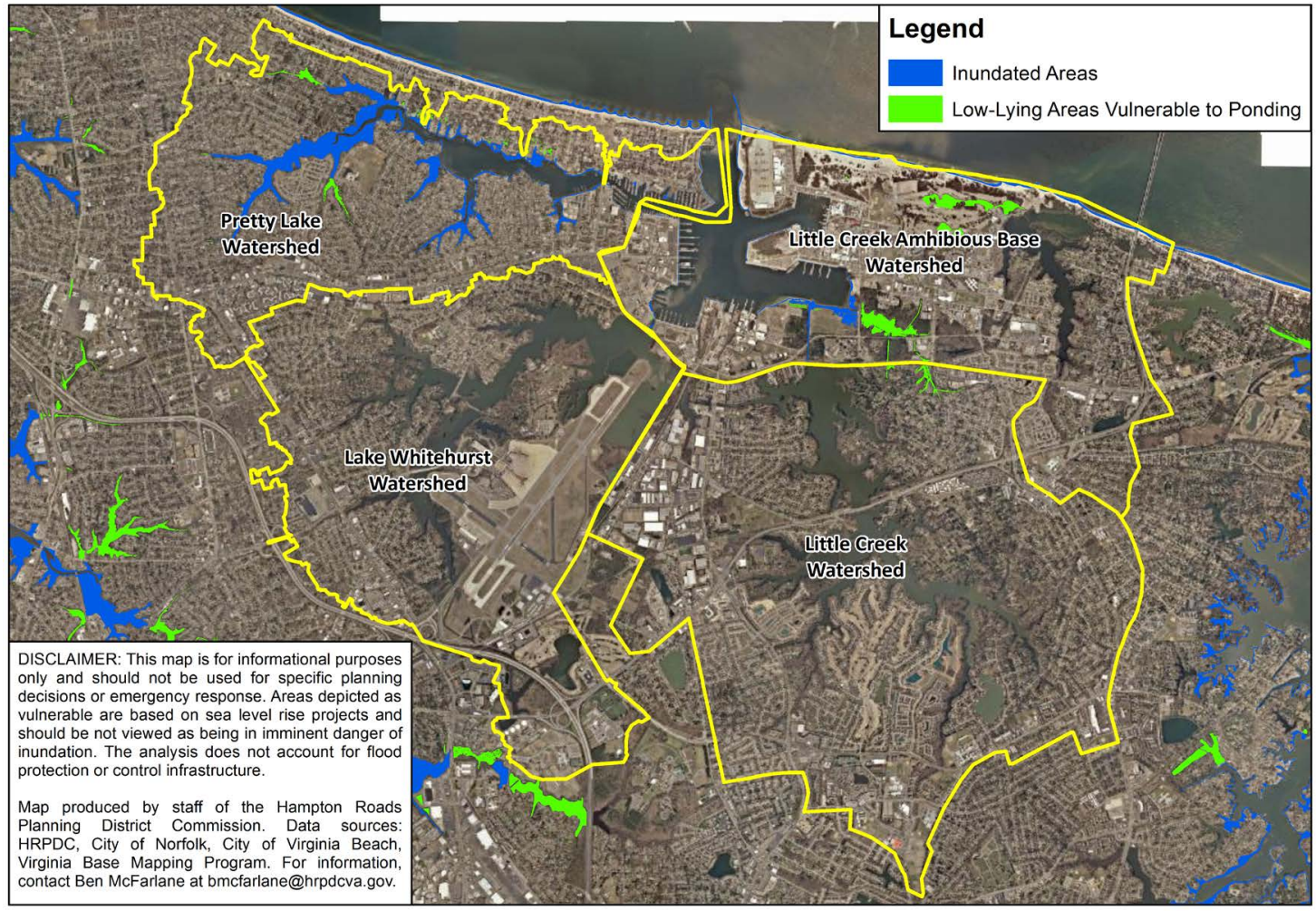

Figure 3. Case study area map, 1.5' of sea level rise. Map produced by the staff of the Hampton Roads Planning District Commission, 2016. 


\section{5' of Sea Level Rise with 100-year Storm Surge}

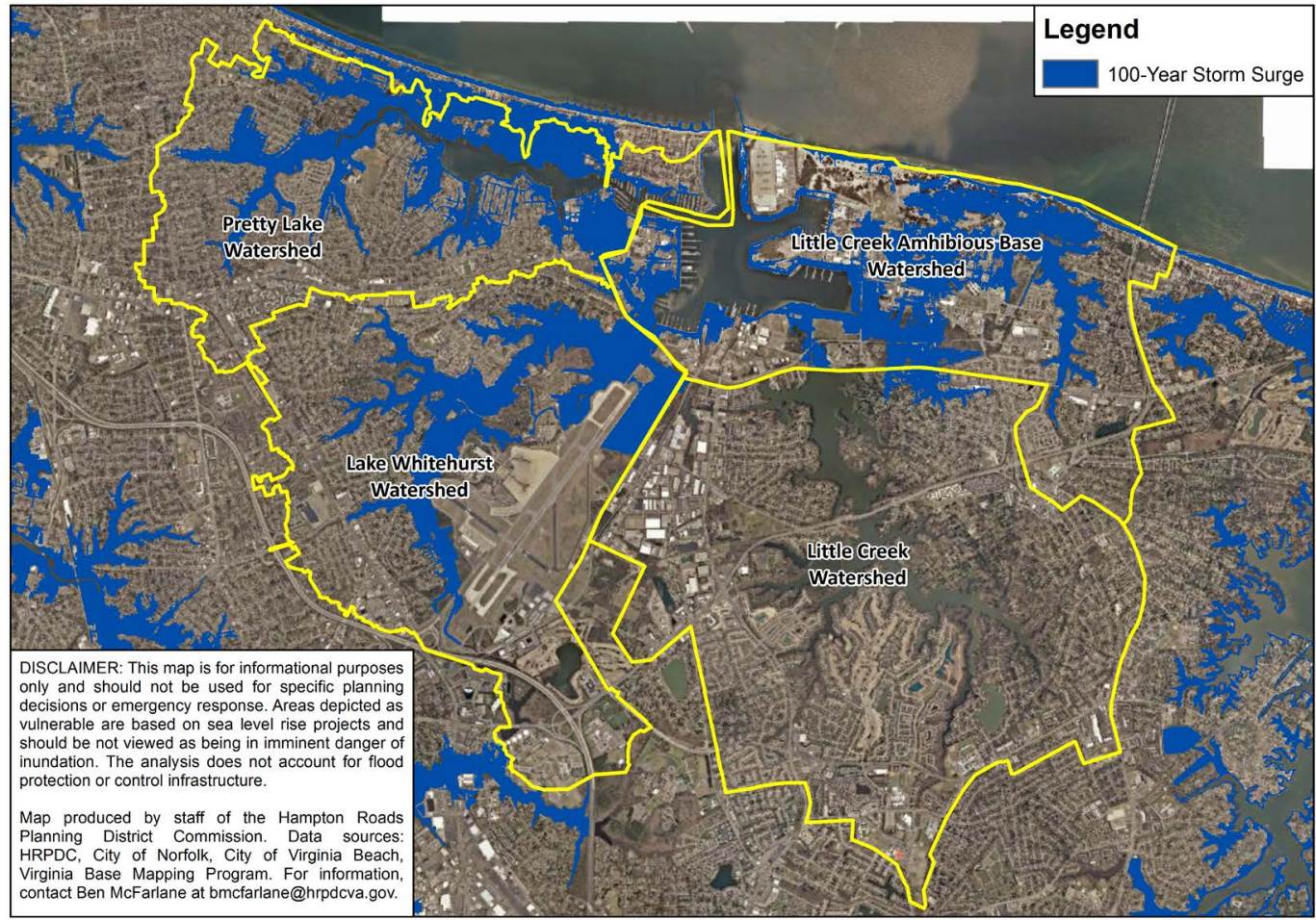

Figure 4. Case study area map, 1.5' of sea level rise with 100-year storm surge. Map produced by the staff of the Hampton Roads Planning District Commission, 2016.

\section{3' of Sea Level Rise Above Current Mean Higher High Water (MHHW)}

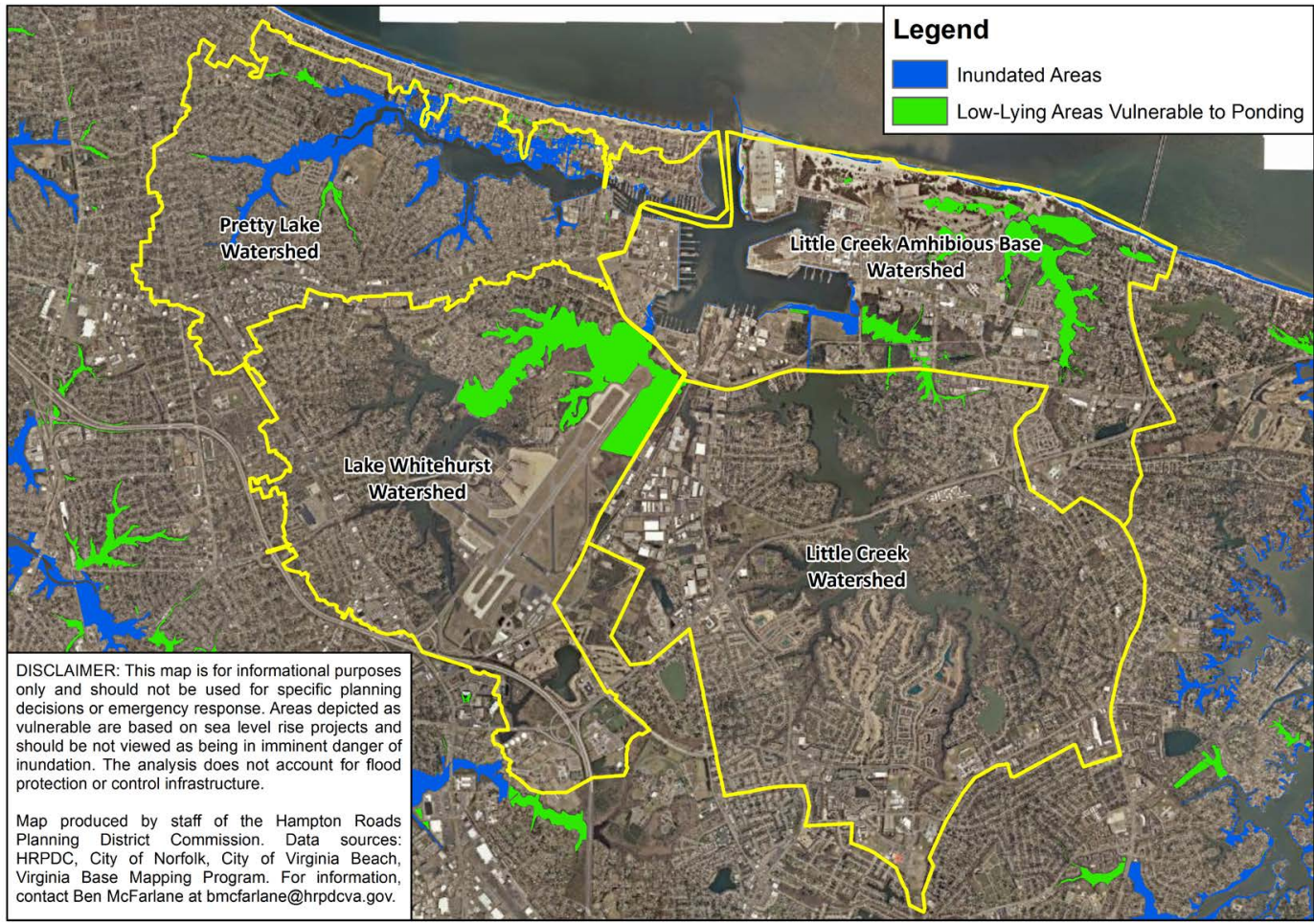

Figure 5. Case study area map, 3' of sea level rise. Map produced by the staff of the Hampton Roads Planning District Commission, 2016. 


\section{3' of Sea Level Rise with 100-year Storm Surge}

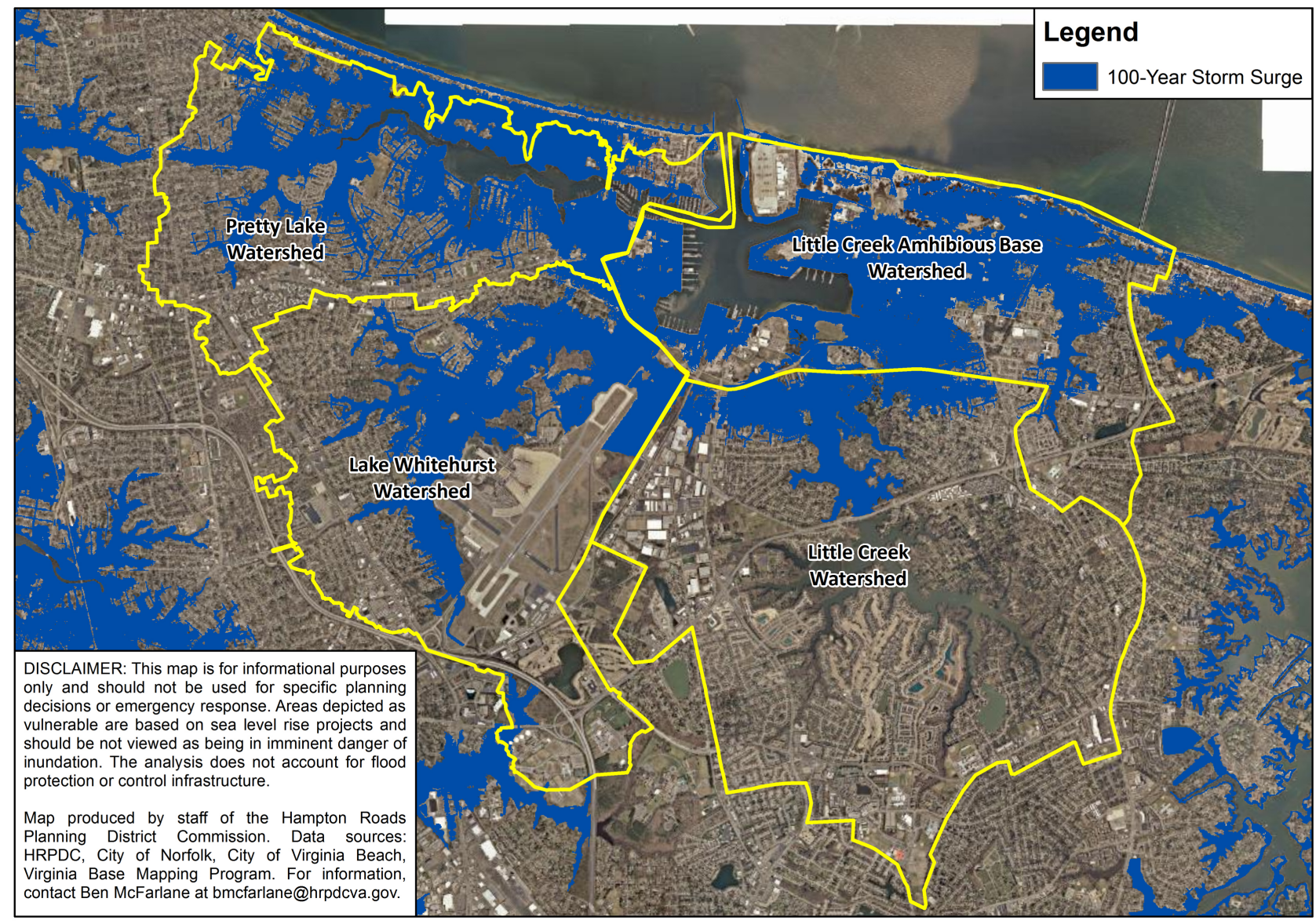

Figure 6. Case study are map, 3' of sea level rise with 100-year storm surge. Map produced by the staff of the Hampton Roads Planning District Commission, 2016.

These scenarios allow for the evaluation of sea level rise and the impact of low probability or infrequent, but high impact flooding events. When evaluating sea level rise impacts, it is important to consider downscaled or regional sea level rise data. The Center for Coastal Resource Management has developed a Sea Level Rise Risk and Vulnerability Tool that includes curves for Southeastern Virginia based on the 2012 National Climate Assessment [17]. Three curves were selected: 1) "highest" based on climate change and maximum contribution from ice sheet loss and glacial melting; 2) "high" based on global observation of sea level and air temperature; and 3) "low" based on the IPCC fourth assessment model. The estimated year of inundation for the case study area under these three scenarios are provided in Table 1.

\subsection{A Multi-Sectoral, Whole-of-Community Approach}

Sea level rise, like climate change in general, is a "super wicked" problem where political and economic forces tend to promote short-term fixes over more difficult long-term solutions [18], largely due to the inherent uncertainty, lack of a central authority to address the problem, and propensity to discount the future 
Table 1. Estimated year of inundation based on relative sea level rise curves for southeastern Virginia.

\begin{tabular}{cccc}
\hline $\begin{array}{c}\text { Case study sea level rise } \\
\text { scenario (ft.) }\end{array}$ & Low curve & High curve & Highest curve \\
\hline 1.5 & 2060 & 2044 & 2032 \\
3.0 & $>2100$ & 2070 & 2054 \\
\hline
\end{tabular}

[19]. Governments, businesses or residents alone cannot address the problem of sea level rise. Instead, they need to work together in a collaborative approach involving multiple sectors and spanning municipal boundaries through a regional approach [10]. As Moser would argue, there is a need to be more cognizant of the actual capacity of communities, businesses, and government institutions to respond and adapt [20]. This multi-sectoral approach is important especially for understanding risks of sea level rise in an integrated way, as the risks are not constrained, span legal, geo-political, and sectoral boundaries. Furthermore, the innovative solutions needed to more effectively adapt to sea level rise requires all sectors-government, business, non-profit, and civil society-be involved.

Such a multi-sectoral approach is consistent with the whole-of-community approach that underpins the Pilot Project. The whole-of-community approach, developed by the Federal Emergency Management Agency, emphasizes the value and importance of strengthening existing relationships and channels of communication between the full array of stakeholders, including local, regional, state and federal governments; non-governmental, faith-based and non-profit organizations; the private sector industry; educational, healthcare and other institutional stakeholders; and individuals, families and communities [21] [22].

\subsection{Infrastructure at Risk, Dependencies and Interdependency Evaluation}

Key to the Pilot Project's institutional framework is the understanding that socio-ecological resilience requires addressing complex human-environment interactions to balance the interdependent social and ecological goals of sustainability and resilience [23] [24] [25]. To do this, the Infrastructure Working Group, in conjunction with the Private Infrastructure Advisory Committee, focused on identifying critical infrastructure in the case study area that are at risk to sea level rise and flooding. Critical infrastructure evaluated included: electrical, drinking water treatment and distribution, water supply, wastewater collection and treatment, and health/hospitals.

In order to understand dependencies (internal and external) of the critical infrastructure, members of the Working Group and Advisory Committee mapped internal dependencies (i.e., dependencies within the system), and external dependencies (i.e., dependencies on other infrastructure systems). The group's assessment of internal dependencies required the development of a list of internal factors that affect operations for each infrastructure system. For example, inter- 
nal factors for a hospital system might include: drinking water, power, communications, staff, wastewater, HVAC, security, computer systems, medical gas, and sustenance and supplies. Once a list of internal factors was established, that list was evaluated to determine vulnerability under the different sea level rise and storm surge scenarios. The evaluation of vulnerability was based on a scale of: not vulnerable (no impact), low vulnerability (less than $33 \%$ of impact), medium vulnerability (less than $66 \%$ of impact), and high vulnerability (system impact greater than 66\%).

Each system was also evaluated based on the dependencies of the internal factors on external infrastructure systems. For example, a hospital's internal factors would be evaluated against the following external infrastructure systems: drinking water supply, electric, gas, communications (data/internet), communications (voice), air transportation, roads, rail, shipping, wastewater collection and treatment, medical facilities, federal facilities, emergency services, and vehicle fuel. The infrastructure was then assessed according to the extent to which its internal operations depend the respective external infrastructure systems. The evaluation of threat to internal operations was based on a scale of: no threat (no impact); low threat (less than 33\% impact); medium threat (less than 66\% impact) and high vulnerability threat (system impact greater than 66\%). In evaluating threat to internal operations, the existence of emergency planning was taken into account. For example, hospital systems may have a 72-hour emergency electrical supply or wastewater pumping stations may have a 24-hour emergency power back-up system.

Evaluation of infrastructure internal and external dependencies was combined into an overall assessment of risk and threat that spanned the entire case study area, irrespective of jurisdictional boundaries. Key findings include:

- The scenario of $1.5^{\prime}$ of sea level rise will have no threat to critical infrastructure systems. Systems have already been hardened or are located at elevations where there is not an impact and no critical areas are inundated.

- The scenario of $1.5^{\prime}$ of sea level rise with 100 -year storm surge will have some threat to all infrastructure systems evaluated. There is a low threat to the medical facility, and City of Norfolk water supply and water distribution systems. There is a medium threat to electrical infrastructure and City of Norfolk wastewater and a medium threat to City of Virginia Beach wastewater and drinking water distribution.

- The scenario of 3.0' of sea level rise will have relatively low threat to City of Norfolk water supply, water distribution and wastewater systems. The City of Virginia Beach has a low threat to the collection system of their wastewater but no threat to the other parts of the system.

- The scenario of 3.0' of sea level rise with 100-year storm surge will have a high level of threat to a portion of all infrastructure systems evaluated in the case study area except for one hospital which is located on relatively high ground just outside of the case study area.

During the process of evaluating critical infrastructure systems in the case 
study area, several key insights were noted. First, in the case study area, sea level rise will not have a major impact on infrastructure systems, but the addition of storm surge with sea level rise will create significant problems. Second, the City of Norfolk and City of Virginia Beach use different power back-up systems for their pumping stations, with City of Virginia Beach using natural gas for backup power and City of Norfolk using petroleum based back-up generators. This information was previously not shared between jurisdictions. Finally, the assessment process underscored that infrastructure evaluation results will vary based on the location within the region in which the analysis is completed and the vulnerability of the specific area to sea level rise and flooding related to storm surge.

\subsection{Citizen Engagement, Education, and Participation in Decision Making}

The Little Creek/Pretty Lake case study also involved a citizen engagement component to supplement the whole-of-government approach of the critical infrastructure assessment with a whole-of-community component. By involving citizens and other stakeholders in environmental decision-making, the quality of information, the range of possible responses and popular support for eventual solutions increase, while also improving the community's capacity to deal with future decisions when social learning changes the way they understand and engage with the socio-ecological system. Tools that improve the effectiveness of a public participation process, such as those that allow a better understanding of risk perception and that mainstream potentially controversial decision processes, help organizations that bridge science and decision-making move past barriers to building resilience. To prepare for sea level rise, the process of developing adaptation plans can help communities to reduce risk by involving a broad range of interest groups, identifying the greatest threats to human lives and property, and finding strategies to address those threats. Understanding how people consider threats to lives and property and prioritize their concerns is an important part of developing strategies that municipalities can implement effectively. Decisions made with the participation of the affected public are likely to be of better quality and legitimacy [26]. Public engagement in decision-making can produce diffuse but long-lasting positive outcomes, such as the establishment of better communications between stakeholders and public officials [26] [27]. If scientific and management experts, residents, and decision-makers are included in a process that balances knowledge and power dynamics, the resulting plan is more likely to have better efficacy and acceptance in the community [28].

\subsection{Case Study Informing the Regional Response to Sea Level Rise Adaptation Strategies}

The Pilot Project's Community Engagement Working Group was also involved in the Little Creek/Pretty Lake case study. Focus group meetings were conducted using the Action-Oriented Stakeholder Engagement for a Resilient Tomorrow 
(ASERT) framework. ASERT is designed to facilitate engagement of stakeholders across multiple sectors in enhancing community resiliency. The foundation of this engagement framework is the presentation of relevant and accessible information, use of two-way communication and deliberative and participative mechanisms [29] [30] [31]. The deliberative and participatory approach builds on the Structured Public Involvement approach that has been applied in highconflict decision making contexts such as environmental and transportation planning [32] [33] [34].

The focus group used participatory mapping to obtain local knowledge about the location of valued assets within the community and locations challenged by increasing flooding. The benefits of using participatory mapping include introducing new and varied perspectives, creating usable information, promoting active learning, and surfacing unexamined assumptions [35]. By having stakeholders collectively define the problem and identify possible solutions and strategies, it also allows for the co-production of practice- and policy-relevant knowledge that are grounded in stakeholder values and the local context, enabling the design of adaptation processes with context-specific information [36] [37] [38]. This is particularly relevant when the problem and solutions span multiple jurisdictions and affect various agencies, organizations, and communities. The focus group also included two-way dialog and group deliberation around three questions: 1) How do we adapt to protect community assets or address the challenges? 2) Why do we need to do this? and 3) What is preventing us from doing this? This format allows for social learning among participants, which is important because social learning offers a process of social change through which individuals can learn from one another in ways that can benefit wider social-ecological systems [39] [40].

Forty residents participated over four focus group meetings, with just over half having some military affiliation (e.g., active duty, reservist, veteran, and their spouse or family member). This strong representation of military-affiliated stakeholders was not surprising given the geography of the case study location. Focus group participants were presented with maps of the Little Creek neighborhoods including flood scenarios previously identified by the Infrastructure Working Group. The participatory mapping exercise identified key community assets, such as parks and recreational centers, churches, restaurants, stores, and fire stations, as well as community-level challenges such as flooded bridges and roads, sewage backups, flooded homes, and isolation of community assets due to lack of access. The participatory mapping exercise also underscored how military facilities, and their associated support infrastructure, are interwoven into the fabric of community life. Focus group participants identified the Little Creek Base to be a primary asset in the community, and that the inability to access the base due to flooding is a key challenge faced by the community. At a more detailed level, specific components of the base, such as the commissary and the clinic, were also pinpointed as assets. These findings emphasize the point that the impacts of sea level rise and flooding are not constrained by political boun- 
daries, since the lack of access to military facilities can pose challenges both to military personnel and members of the community.

Deliberation among the focus group participants focused on perceptions and preferences for adaptation methods, including traditional engineered structural elements, such as flood walls, natural elements, and non-structural approaches, such as planning and policy. Following the structured discussion about adaptation to protect community assets or address challenges, focus group participants also prioritized different adaptation methods using audience response tools. When asked to select the top three adaptation actions they believed to be most feasible for improving their community's resilience to sea level rise and/or flooding, they identified natural solutions (e.g., dunes and beaches, wetlands, oyster reefs, maritime forests and shrubs), flood warning and preparedness, and floodplain policy and management as the top actions.

\section{Institutional Mechanisms to Enable Collaborative Solutions}

Responding to sea level rise in a way that spans multiple jurisdictions and governments provides "one way in which many of the barriers related to inter-jurisdictional context may be transformed into enablers of action" [41] (p. 294). However, the Pilot Project case study highlights the importance of having in place mechanisms that allow and facilitate collaborative solutions that span the different legal, political, and geographical boundaries. Ford and King identified several types of constraints to adaptation readiness that may manifest when multiple institutions at different scales and with different organizational boundaries are involved [42]. These include limited interactions between organizations and their actors, conflicting objectives, ambiguity over responsibility for actions, and, ultimately, failure of collective decision making.

Applying the Ford and King adaptation readiness framework to the Hampton Roads region St. John III and Yusuf identified the lack of multi-sectoral rapport and consensus on a regional scale as a key challenge that detracts from adaptation readiness [43]. In a finding that resonates strongly with the tenor of the landscape of this Pilot Project case study, they note that key actors and decision makers "can certainly feel more capability to develop options within their own organizational structure, but they may not see an effective region-wide and cross-sectoral framework within which to implement those options ... [and] no visible way to put them into place across a larger group of actors in a wider geographic space" [43].

St. John III and Yusuf further point to the need for boundary spanning and enabling adaptation collaborations across sectoral and organizational boundaries, recognizing that such collaborations hinge on having organizations able to work within a wider ecology of forces (e.g., organizational, structural, and environmental) [43]. Their findings are consistent with the work of Tribbia and Moser [44] on the need for "boundary organizations that can play the intermediary role of co-producing knowledge resources between science and manage- 
ment" [43]. A boundary organization is a governmental agency, academic unit, or non-governmental organization that serves as an intermediary and has structures for accountability [45].

The Pilot Project offers an institutional framework that serves as a boundary quasi-organization that focused on bringing together mid-level managers from different private industries, local governments and federal agencies. Boundary spanning efforts at this level allow for the breaking down of stove pipes across the different organizations. Boundary organizations can also facilitate public participation processes to achieve goals of fair deliberations and unbiased processes by incorporating values from multiple stakeholders to connect sides into a workable relationship. Some organizations establish long-term associations with particular stakeholders, and use processes to increase the social capacity of stakeholders so that they can be involved in planning and management [46].

Monthly meetings of the Private Infrastructure Advisory Committee and Infrastructure Working Group bridged fragmented private industry, local government and federal agencies. These meetings allowed mid-level managers from municipal governments, federal installations, and state agencies across infrastructure systems to collaborate on problem solving, and share information on systems that previously was not available across entities. Additionally, meetings outside of the Pilot Project introduced agency representatives, reduced barriers to collaboration, and facilitated sharing of infrastructure information. Specific examples include meetings between City of Virginia Beach, City of Norfolk and Little Creek Amphibious Base to discuss the Little Creek/Pretty Lake Case Study and meetings between the Department of Energy and Virginia Dominion Power to discuss potential exposure of electrical assets in the region to sea level rise and storm surge.

The work of Dow et al. in North Carolina and South Carolina found that intra and cross-sector networks can support adaptation by including key elements such as involving multiple organizations, involving local leaders, access to funding, and access to pre-existing networks [47]. While some of these elements were present in the Pilot Project case study, others-for example, access to fundingcould be introduced to further facilitate and encourage boundary spanning efforts.

\section{Conclusions}

The Hampton Roads Intergovernmental Pilot Project provides an institutional arrangement that enables a whole-of-government and whole-of-community approach to enhancing socio-ecological resilience. It plays an important role in addressing the challenges resulting from spatial mismatches that arise from most attempts to address issues related to socio-ecological resilience. As highlighted in the Little Creek/Pretty Lake case study, the Pilot Project facilitated boundary spanning and working across legal, political, geographical, and ecological boundaries. This successfully allowed for identification of dependencies across critical infrastructure systems, and an integrated assessment of vulnerability of infra- 
structure to sea level rise and storms. As a bridging organization, the Pilot Project, served an important function in "knowledge coproduction, trust building, sense making, learning, vertical and horizontal collaboration, and conflict resolution" [48] by catalyzing and facilitating interactions among the various entities and stakeholders involved in managing the socio-ecological system, across resource and knowledge systems [12].

The case study also illustrates the importance of social learning in addressing scale mismatches. Through its boundary spanning, bridging, and community engagement roles, the Pilot Project's institutional structure emphasized social sources of resilience, and particularly social capital, such as trust and social networks, and social memory [12].

Long-term solutions to scale mismatch problems will depend on social learning and the development of flexible institutions that can adjust and reorganize in response to changes in ecosystems [14]. Lee also emphasizes the role of learning in understanding the mismatches between human responsibility and natural interactions [13]. It is important to note that in our case study, social learning is useful for resolving spatial mismatches and can also play a role in addressing functional and temporal mismatches. Functional and temporal mismatches may pose scale mismatch issues in the future, as the region learns from the experiences with the Pilot Project and continues on its current path towards addressing socio-ecological resilience. As the Hampton Roads region continues to organize across jurisdictional and sectoral boundaries, it will become more resilient if it stays attuned to potential functional and temporal scale mismatches while remaining focused on building the capacity for learning and adaptation.

\section{References}

[1] Institute for Environmental Negotiation (2011) Sea Level Rise in Hampton Roads: Findings from the Virginia Beach Listening Sessions. Institute for Environmental Negotiation, University of Virginia, Charlottesville.

[2] Boon, J.D. (2012) Evidence of Sea Level Acceleration at US and Canadian Tide Stations, Atlantic Coast, North America. Journal of Coastal Research, 28, 1437-1445. https://doi.org/10.2112/JCOASTRES-D-12-00102.1

[3] Ezer, T. and Corlett, W.B. (2012) Is Sea Level Rise Accelerating in the Chesapeake Bay? A Demonstration of a Novel New Approach for Analyzing Sea Level Data. Geophysical Research Letters, 39, L19605. https://doi.org/10.1029/2012gl053435

[4] Sallenger, A.H., Doran, K.S. and Howd, P.A. (2012) Hotspot of Accelerated SeaLevel Rise on the Atlantic Coast of North America. Nature Climate Change, 2, 884888. https://doi.org/10.1038/nclimate1597

[5] Boon, J.D., Brubaker, J.M. and Forrest, D.R. (2010) Chesapeake Bay Land Subsidence and Sea Level Change. Applied Marine Science and Ocean Engineering, 425, $1-73$.

[6] Ezer, T., et al. (2013) Gulf Stream's Induced Sea Level Rise and Variability along the US Mid-Atlantic Coast. Journal of Geophysical Research: Oceans, 118, 685-697.

[7] Noorgard, R.B. (1994) Development Betrayed: The End of Progress and Coevolutionary Revisioning of the Future. Routledge, London.

[8] Adger, W.N. (2000) Social and Ecological Resilience: Are They Related? Progress in 
Human Geography, 24, 347-364. https://doi.org/10.1191/030913200701540465

[9] Folke, C. (2006) Resilience: The Emergence of a Perspective for Social-Ecological Systems Analyses. Global Environmental Change, 16, 253-267. https://doi.org/10.1016/j.gloenvcha.2006.04.002

[10] Adger, W.N., et al. (2005) Social-Ecological Resilience to Coastal Disasters. Science, 309, 1036-1039. https://doi.org/10.1126/science.1112122

[11] Dietz, T., Ostrom, E. and Stern, P.C. (2003) The Struggle to Govern the Commons. Science, 302, 1907-1912. https://doi.org/10.1126/science.1091015

[12] Folke, C., et al. (2005) Adaptive Governance of Social-Ecological Systems. Annual Review of Environment and Resources, 30, 441-473. https://doi.org/10.1146/annurev.energy.30.050504.144511

[13] Lee, K. (1993) Greed, Scale Mismatch, and Learning" 2. Ecological Applications, 3, 560-564.

[14] Cumming, G.S., Cumming, D.H. and Redman, C.L. (2006) Scale Mismatches in Social-Ecological Systems: Causes, Consequences, and Solutions. Ecology and Society, 11, 14. https://doi.org/10.5751/ES-01569-110114

[15] Borgström, S.T., et al. (2006) Scale Mismatches in Management of Urban Landscapes. Ecology and Society, 11, 16. https://doi.org/10.5751/ES-01819-110216

[16] Fugro Atlantic (2012) Preliminary Engineering Feasibility Report-Pretty Lake Watershed (March 2012). Project Number 04.8111024. http://www.norfolk.gov/DocumentCenter/View/1774

[17] Center for Coastal Resource Management (2016) Sea Level Rise Inundation ToolUser Guide. http://ccrm.vims.edu/ccrmp/SLR_User_Guide.pdf

[18] Lazarus, R.J. (2008) Super Wicked Problems and Climate Change: Restraining the Present to Liberate the Future. Cornell Law Review, 94, 1153.

[19] Levin, K., et al. (2012) Overcoming the Tragedy of Super Wicked Problems: Constraining Our Future Selves to Ameliorate Global Climate Change. Policy Sciences, 45, 123-152. https://doi.org/10.1007/s11077-012-9151-0

[20] Moser, S.C. (2010) Now More Than Ever: The Need for More Societally Relevant Research on Vulnerability and Adaptation to Climate Change. Applied Geography, 30, 464-474. https://doi.org/10.1016/j.apgeog.2009.09.003

[21] Federal Emergency Management Agency (2011) A Whole Community Approach to Emergency Management: Principles, Themes, and Pathways for Action. Federal Emergency Management Agency, Washington DC.

[22] Centers for Disease Control and Prevention (2013) Building a Learning Community and Body of Knowledge: Implementing a Whole Community Approach to Emergency Management.

http://www.cdc.gov/phpr/documents/whole_community_program_report_october 2013.pdf

[23] Clark, W.C. (2007) Sustainability Science: A Room of Its Own. Proceedings of the National Academy of Sciences, 104, 1737. https://doi.org/10.1073/pnas.0611291104

[24] Wilkinson, C., et al. (2013) Strategic Spatial Planning and the Ecosystem Services Concept-An Historical Exploration. Ecology \& Society, 18, 37. https://doi.org/10.5751/ES-05368-180137

[25] Wu, J. (2013) Landscape Sustainability Science: Ecosystem Services and Human Well-Being in Changing Landscapes. Landscape Ecology, 28, 999-1023. https://doi.org/10.1007/s10980-013-9894-9

[26] National Research Council (2008) Public Participation in Environmental Assess- 
ment and Decision Making. National Academies Press, Washington DC.

[27] Beierle, T.C. (2000) The Quality of Stakeholder-Based Decisions: Lessons from the Case Study Record. Resources for the Future, Washington DC.

[28] Leys, A.J. and Vanclay, J.K. (2011) Social Learning: A Knowledge and Capacity Building Approach for Adaptive Co-Management of Contested Landscapes. Land Use Policy, 28, 574-584. https://doi.org/10.1016/j.landusepol.2010.11.006

[29] Coles, E. and Buckle, P. (2004) Developing Community Resilience as a Foundation for Effective Disaster Recovery. Australian Journal of Emergency Management, 19, 6-15.

[30] Vogel, C., et al. (2007) Linking Vulnerability, Adaptation, and Resilience Science to Practice: Pathways, Players, and Partnerships. Global Environmental Change, 17, 349-364. https://doi.org/10.1016/j.gloenvcha.2007.05.002

[31] Cutter, S.L., et al. (2008) A Place-Based Model for Understanding Community Resilience to Natural Disasters. Global Environmental Change, 18, 598-606. https://doi.org/10.1016/j.gloenvcha.2008.07.013

[32] Bailey, K., Brumm, J. and Grossardt, T. (2002) Integrating Visualization into Structured Public Involvement: Case Study of Highway Improvement in Central Kentucky. Transportation Research Record, 1817, 50-57. https://doi.org/10.3141/1817-07

[33] Bailey, K., et al. (2007) Structured Public Involvement in Context-Sensitive Large Bridge Design Using Casewise Visual Evaluation: Case Study of Section 2 of Ohio River Bridges Project. Transportation Research Record: Journal of the Transportation Research Board, 2028, 19-27. https://doi.org/10.3141/2028-03

[34] Bailey, K., et al. (2011) Planning, Technology, and Legitimacy: Structured Public Involvement in Integrated Transportation and Land-Use Planning in the United States. Environment and Planning B: Planning and Design, 38, 447-467. https://doi.org/10.1068/b35128

[35] Jones, S. (2015) Mapping Coastal Risks and Social Vulnerability: Principles and Considerations.

[36] Few, R., Brown, K. and Tompkins, E.L. (2007) Public Participation and Climate Change Adaptation: Avoiding the Illusion of Inclusion. Climate Policy, 7, 46-59. https://doi.org/10.1080/14693062.2007.9685637

[37] Fazey, I., et al. (2010) Adaptation Strategies for Reducing Vulnerability to Future Environmental Change. Frontiers in Ecology and the Environment, 8, 414-422. https://doi.org/10.1890/080215

[38] Preston, B.L., Yuen, E.J. and Westaway, R.M. (2011) Putting Vulnerability to Climate Change on the Map: A Review of Approaches, Benefits, and Risks. Sustainability Science, 6, 177-202. https://doi.org/10.1007/s11625-011-0129-1

[39] Reed, M., et al. (2010) What Is Social Learning? Ecology and Society, 15, r1. https://doi.org/10.5751/ES-03564-1504r01

[40] Bandura, A. and McClelland, D.C. (1977) Social Learning Theory. Prentice Hall, Englewood Cliffs.

[41] Burch, S. (2009) Transforming Barriers into Enablers of Action on Climate Change: Insights from Three Municipal Case Studies in British Columbia, Canada. Global Environmental Change, 20, 287-297. https://doi.org/10.1016/j.gloenvcha.2009.11.009

[42] Ford, J.D. and King, D. (2015) A Framework for Examining Adaptation Readiness. Mitigation and Adaptation Strategies for Global Change, 20, 505-526. https://doi.org/10.1007/s11027-013-9505-8 
[43] St. John III, B. and Yusuf, J.-E.W. (2016) Assessment of Regional Adaptation Readiness and Barriers to Adaptation: Perspectives of Experts and the Experienced. Western Regional Science Association.

[44] Tribbia, J. and Moser, S.C. (2008) More Than Information: What Coastal Managers Need to Plan for Climate Change. Environmental Science and Policy, 11, 315-328. https://doi.org/10.1016/j.envsci.2008.01.003

[45] Crona, B.I. and Parker, J.N. (2012) Learning in Support of Governance: Theories, Methods, and a Framework to Assess How Bridging Organizations Contribute to Adaptive Resource Governance. Ecology and Society, 17, 32. https://doi.org/10.5751/ES-04534-170132

[46] Brewer, J.F. (2013) From Experiential Knowledge to Public Participation: Social Learning at the Community Fisheries Action Roundtable. Environmental Management, 52, 321-334. https://doi.org/10.1007/s00267-013-0059-z

[47] Dow, K., et al. (2013) The Role of Ad Hoc Networks in Supporting Climate Change Adaptation: A Case Study from the Southeastern United States. Regional Environmental Change, 13, 1235-1244. https://doi.org/10.1007/s10113-013-0440-8

[48] Berkes, F. (2009) Evolution of Co-Management: Role of Knowledge Generation, Bridging Organizations and Social Learning. Journal of Environmental Management, 90, 1692-1702. https://doi.org/10.1016/j.jenvman.2008.12.001

\section{Submit or recommend next manuscript to SCIRP and we will provide best} service for you:

Accepting pre-submission inquiries through Email, Facebook, LinkedIn, Twitter, etc. A wide selection of journals (inclusive of 9 subjects, more than 200 journals)

Providing 24-hour high-quality service

User-friendly online submission system

Fair and swift peer-review system

Efficient typesetting and proofreading procedure

Display of the result of downloads and visits, as well as the number of cited articles

Maximum dissemination of your research work

Submit your manuscript at: http://papersubmission.scirp.org/

Or contact ajcc@scirp.org 